\title{
Guidelines for Cloud Computing Architecture:Development Process
}

\author{
Raja Muhammad Ubaid Ullah ${ }^{\# 1}$, Dr.Kevan A. Buckley ${ }^{\# 2}$, Dr. Mary Garvey ${ }^{\# 3}$, Dr. Jun Li ${ }^{\# 4}$. \\ School of Mathematics and Computer Science \\ University of Wolverhampton, Wulfruna Street, Wolverhampton WVI ILY, UK.
}

\begin{abstract}
Cloud computing (CC) has received significant attention from different types of businesses and Industries and emerged as a new utility for businesses activities. The philosophy behind CC shows a great potential to transform a major part of the IT industry, making computing environment and resources even more attractive as a cost-effective service and changing the way IT hardware is designed and purchased. Resulting day by day more small and medium and large enterprise are adopting different types of CC services. However, strong market competitive environment for converting existing IT services to CC environment imposed different types of challenges for the $C C$ architect. Development of CC architect environment in any organisation is a very complex process and success depends on its proper architecture design and development according to business requirements. The aim of this paper identifies the major type of key factors from literature and provides different guidelines for organisations to support the $C C$ architecture development process. Finally, the different types of CC services generally referred to as CC architect are explained how they all work. This paper will be helpful and provides certain guidance on situations where specific types of CC services are particularly not the best option for any organization.
\end{abstract}

\section{Keywords}

Cloud, cloud computing, cloud architecture, guidelines, development process, architecture

\section{INTRODUCTION}

The main objective of $\mathrm{CC}$ utilisation is to maximize the effectiveness of shared resources [1]. Therefore, CC becomes the fastest growing technology in today's business market, which result in the easiest availability of computational technology services for business organizations through the internet [2].]. To survive, companies need to find new strategic ideas and implement at a faster pace to achieve a competitive advantage over their challengers within the global market. "The need to quickly respond to business demands is imperative in this new age. Waiting six to eight weeks for a new server deployment is unacceptable" [3]. In CC service models provide different types of services to organisations to perform the business tasks. For instance, Infrastructure as a Service (IaaS), it offers various type of hardware resources in the form of service, for instance, Central Processing Unit (CPU), virtual machine (VM), memory, storage and network devices, etc. [2,7]Platform as a Service (PaaS), it works with the combination of both, infrastructure and application by CSP, to facilitate the user to develop and deploy their respective applications $[2,8]$ and finally Software as a Service (SaaS), it provides a software delivery model, to run various software applications through the Internet without installing these in the client site [2, 9].

Organisations are using traditional application development, which is mainly emphases on practical requirements as they are on-premises deployed application with implicit regulator operation and security. Contrary to that, CC architecture delivers integrated solution over the Internet and some specific $\mathrm{CC}$ applications need time to time innovation and changes. The particular CC architecture design, database partitioning, database architecture, scalability issues, user interface design, use of APIs and workflow is different from tradition application [10, 11].Whereas, CC architect should be able to retain a comparativelyhigherlevelofquality rather thana conventionalsystem. The $\mathrm{CC}$ architect development requires a relatively different methodology than the traditional IT architect. Comparatively, it should be designed and developed inawaysoitcaninfluencethep a r t i c u lar benefitsdeliveredbythecloud-oriented computing platform.

\section{A GUIDE TO CLOUD DATA}

Guide to cloud data focus on many different kinds, or flavours, of cloud data and they need to be addressed differently [12].

According to Gordon Haff, cloud evangelist for open source platform company Red Hat. "It's worth remembering that there are many different kinds, or indeed flavours, of cloud data and they need to be 
treated differently. Data that's used for monitoring might be appropriate for a time-series database. But even big data isn't a singular thing. Data may be big in volume, which brings its own sets of challenges to store it and, especially, to move it. But data may also be big in terms of how quickly it needs to be processed and so it requires the data to be close to the applications using it".

\begin{tabular}{|l|l|}
\hline \multicolumn{2}{|c|}{ Different Flavours of Cloud Data } \\
\hline Structured & $\begin{array}{l}\text { Structured data belongs to an application and has a specific value, size and } \\
\text { meaning. }\end{array}$ \\
\hline Unstructured & $\begin{array}{l}\text { Unstructured or semi-structured data also often belongs to an application, but it } \\
\text { could take the form of sound, video or some other more difficult to quantify and } \\
\text { quality block of information. }\end{array}$ \\
\hline Time Series & $\begin{array}{l}\text { Time series data, which in simple terms is just information with a note of when it } \\
\text { was created. }\end{array}$ \\
\hline Spatial / Geospatial & Spatial or geospatial data usually refers to descriptions of physical objects. \\
\hline Orphan & $\begin{array}{l}\text { Orphan data, you guessed it, doesn't have a home application or wider data set } \\
\text { family that it belongs to. }\end{array}$ \\
\hline Meta & $\begin{array}{l}\text { Meta data, which is higher level data dedicated to providing information about } \\
\text { other pieces of information. }\end{array}$ \\
\hline Log File/Machine & $\begin{array}{l}\text { This is data an events that occur in software and operating systems from the } \\
\text { information channels that computers generate so they can record every single } \\
\text { click and function in their universe, and they also often use it to talk to other } \\
\text { machines. }\end{array}$ \\
\hline
\end{tabular}

Table 1:Different Flavours of Cloud Data.

\section{CC LOOK QUITE DIFFERENT IN A FEW YEARS.}

Two years ago, Wired ran an arresting headline: "The Cloud Computing Era Could Be Nearing Its End" [16]. But that view of the future now seems unlikely. LinkedIn has said the number-one hard skill companies are looking for in 2019 is a facility with cloud computing $[13,17]$.

\section{What are hard and soft skills?}

While hard skills concern your ability to do a specific task, soft skills are more about the way you do them, e.g., the way you adapt, collaborate, or make decisions.

Hard skills include specialized knowledge and technical abilities, like software development, tax accounting, or patent law expertise. As such, they're often easier to define and measure than soft skills.Soft skills are more about your behaviour or thinking - your personal characteristics and cognitive skills [17].

And speaking to CNBC last November, Daniel Zhang, CEO of Chinese e-commerce giant Alibaba, said not only that cloud computing will become Alibaba's "main business" but that "every business will rely on the cloud in the future." $[13,18]$.
The rapid growth in $\mathrm{CC}$ usage, mostly everything in the digital world is already connected in some way to the cloud, with the only exception being data stored locally for security reasons. LogicMonitor's 'Cloud Vision 2020: The Future of the Cloud' study concluded that 83 percent of enterprise workloads will be in the cloud in a year's time, while a 2018 SmartCompany report found that cloud technology came second only to smartphones in terms of impact on business efficiency over the past five years.

Based on these circumstances, it's more likely to imagine that in the coming future, it might in five or 10 years from now - almost all businesses will prefer to operate primarily from the cloud, which has implications for cost-efficiency, productivity and flexibility.

\section{A. User experience}

Theuser experience will be on the priority list. The main reasons Apple came to dominate the smartphone market. Therefore, more likely attention paid to design and to create a "cleaner," simpler design that will easily appeal to the average consumer used to basic smartphone apps and to the less digitally literate [13, $19]$.

\section{B. Desktop-as-a-Service (DaaS)}

The use of Desktop-as-a-Service (DaaS), which describes as the operation of a virtual desktop infrastructure by a third party. Therefore, employee's 
personal data of a business, for instance, could be copied to and from their respective virtual desktop each time they log on or off, which results creating a virtual working environment that operates rapidly, enable secures information reliably, and mainly organizes itself. Whereas, access to that particular data, meanwhile, will be independent of device, location, or network, which is painless remote-working and a more likely reduction in the likelihood of human error. The Global DaaS Market Report for 2018 forecast that the market for DaaS would increase from $\$ 650$ million in 2017 to $\$ 4.67$ billion by $2022[13,20]$.

\section{App-to-app integration}

There are a number of challenges poses when everything may run on the cloud, but running multiple clouds at the same time, such as compliance with data regulation $[13,21]$.

\section{Cloud as default}

As increasing numbers in the cloud, it may in future the term "cloud" could disappear altogether, which may be the result that companies with "cloud" in their name may need to rethink their branding. As now we call "cloud computing" will simply turn to "computing." And maybe soon, by extension, "as-a-Service" will disappear, too, as SaaS replaces traditional software[13, 22].

\section{THE FUTURE OF CC IN COMING YEARS}

The CC formations basically changing and providing new opportunities for organisations that looking forward for exciting future developments in the industry [14].

\section{A. The cloud is an essential element of any innovative strategy}

According to the approach of Alex von Schirmeister, chief digital, technology and innovation officer at retail specialist RS Components, his firm is becoming increasingly confident when it comes to the cloud. "Our data no longer needs to be sitting on our own infrastructure and data no longer needs to sit in one physical premise - those days are over," he says [12].

Yet the game is far from won. Gregor Petri, research vice president at analyst Gartner, says there is a popular belief the cloud is already a business-as-normal activity. However, this view is a misconception and only a small amount of enterprises run significant workloads on the cloud, he says. "There's still a long way to go," says Mr Petri.
"These new, disruptive technologies, which are too expensive to run today, will make up the majority of things that are running on the cloud in the future," says Mr Petri. These technologies include application programming interfaces, internet of things, artificial intelligence, serverless computing and new interactive services, such as virtual reality and blockchain.

Enterprises will run these innovations on the cloud, agrees Alex Hilton, chief executive of the Cloud Industry Forum (CIF). "Cloud is the generator for the next wave of technologies, the enabler for all the exciting developments," he says. CIF research suggests just 12 percent of IT budgets will be spent on legacy technology by 2022 as cloud usage increases [15].

\section{B. How demand for access to computing power will shape the sector}

$\mathrm{CC}$ provides easy access to computing power and facilitates with exciting possibilities for the future secure and ease of the business environment. "Enterprises will use the cloud as a scalable foundation for the creation of new business models", says Kevin Curran, professor of cybersecurity at Ulster University and a senior member of the Institute of Electrical and Electronics Engineers [14].

"This massive cloud computing power with instant response will make intelligence on demand available for everyone, everywhere. New business models, where devices are boosted by inexhaustible cloud-based resources, will begin to emerge," he says [14].

But independent analyst Clive Longbottom believes most enterprises will continue to use large, hyperscale cloud providers instead of smaller specialists. The major players, such as Amazon Web Services, Microsoft, Google and IBM, wield significant power and this will not wane, he says [14, 23].

"The answer is not a private or a public cloud or even a mix of the two, but a dynamic and mixed cloud of, more often than not, a private cloud mixed with a range of public cloud services, including infrastructure, platform and software-as-a-service," says $\mathrm{Mr}$. Longbottom [14, 24].

\section{Secret to scalability is cloud-first computing strategy}

An assessment of the broad mix of a provision is familiar to Richard Gifford, chief information officer (CIO) at logistics giant Wincanton. "It's about digitally enabling our IT infrastructure," says Mr. Gifford. "The 
aim is to create a cloud-first strategy. This approach will give Wincanton the scalability it needs as business demands change" [14].

The cloud-first use-case demonstrates the increasing maturity of CC. A dynamic, mixed cloud might be the objective, but many organisations still worried that moving data between providers is an intractable challenge [14].

\section{The cloud industry moving towards greater openness}

While vendor lock-in remains a concern, Stephan Fabel, director of product at IT firm Canonical, says the cloud industry and business leaders are showing a new commitment to openness and open-source tools [25]. He says the adoption of "LEGO-like building blocks", through specialist tools such as Kubernetes and OpenStack, will help bring order to the cloud.

According to Barry Libenson, global CIO at financial data company Experian, "I think the good news is the industry is sort of moving in that direction as well," he says. "While some of the cloud providers would love for you to use their native services because of the lockin it potentially creates, I would say the industry is largely focused on flexibility and a recognition that portability is highly desirable" [14].

\section{CLOUD COMPUTING ARCHITECTURE DEFINITION}

Cloud computing architecture defines a set of actors, activities and functions that can be used in the process of developing cloud computing architectures, with the appropriate elements to represent not only application components and their interrelationships. The reference architecture contains a set of views and descriptions that are the basis for discussing the characteristics, uses and standards for cloud computing [27].

\section{CLOUD COMPUTING ARCHITECTURE}

There are five major actors have been identified by NIST in cloud computing [27]. The NIST Conceptual Reference Model diagram in [27, p.4] shows the actors which are discussed below.

Cloud consumer: A person or organisation that maintains a business relationship with, and uses service from Cloud Providers.

Cloud provider: A person, organisation, or entity is responsible for making a service available to interested parties.
Cloud auditor: A party that can conduct an independent assessment of cloud services, information system operation, performance and security of the cloud implementation.

Cloud broker: An entity that manages use, performance and delivery of cloud services, and negotiates relationships between Cloud Providers and Cloud Consumers.

Cloud carrier: An intermediary person, organisation or entity that provides connectivity and transport of cloud services from cloud providers to cloud consumers.

\section{CLOUD COMPUTING ARCHITECTURAL COMPONENTS}

The mentioned below are the main components of CC architecture [28, 48]:

Front-end:The part which is visible to the end-user is called the front-end. This comprises the desktop or any other end-user device (mobile phone, I-pad, etc.), browser and network.

Back-end: The remaining part of the cloud computing architecture is hidden behind the network that comprises various applications, software, computers and data storage devices.

Cloud-based delivery: $\mathrm{CC}$ services are everywhere these days. For instance, if company or individual using Salesforce or QuickBooks, Google Drive or Office 365 at home or work, therefore, you are a cloud computing user.

A network(internet, intranet, Intercloud): Utilisation of CC services can be publicly or privately by using the internet and can also remain within a company's network when provided over an intranet. Sometimes, organizations make use of a combination of both.

Mostly CC architecture can be classified into two sections: front-end and back-end, connected to each other via a virtual network or the internet.

\section{KEY FACTORS FOR CLOUD ARCHITECTURE IMPLICATIONS AND PRINCIPLES}

There are a number of architectural implications that should be observed, to take full advantage of the benefits of Cloud computing [49]. 


\section{A. Business Architecture:}

CC offers exceptional control in assigning resources dynamically to meet the changing requirements of a business. This is only operational when the businesses service level goals have been clearly segmented and guide the cloud's enterprise management layer. Application performance metrics and SLAs must be carefully and clearly documented and also monitored for an effective cloud deployment.

\section{Key Business Architectural Principles}

a. Business Alignment, Cost Optimization.

b. Compliance with Laws and Regulations.

c. Business Agility.

d. Minimize Cost.

\section{B. Application Architecture:}

Application services should abstract resource distribution and avoid the tight binding of its resources to invokers of the service. Dependencies on static references to infrastructure (for instance, storage, servers, network resources), as well as tightly coupled boundaries to dedicated systems, should be avoided.

\section{Key Application Architectural Principles}

a. Technology Independence, Adherence to Standards.

b. Common Development Methodology.

c. Loosely coupled Interfaces.

\section{Information Architecture:}

CCservices offers the potential to utilise information anywhere in the cloud. This service increases the complexity linked with meeting legal and regulatory requirements for sensitive information. Using an Information Asset Management system offers the necessary controls to ensure sensitive information is secure and meets compliance requirements.

\section{Key Information Architectural Principles}

a. Implement Information Lifecycle Management.

b. Regulatory and Legal Compliance.

c. Enforce Data Privacy.

\section{Technology Architecture:}

Implementing Service Oriented Architectures (SOA) offers the maximum effective means of leveraging the abilities of CC. SOAs distributed nature, service encapsulation; defined service level objectives, virtualized interfaces, and adherence to open standards align with Cloud's architectural requirements.

\section{Key Technology Architectural Principles}

a. Control Technical Diversity.

b. Adherence to Standards.

c. Scale Capacity and availability to satisfy Business Objectives.

d. Virtualize dependencies to hardware and software.

e. Unified Security Infrastructure.

\section{ORGANIZATIONAL CONSIDERATIONS}

The successful deployment of CC services within organizations depends on a couple of factors - some technical and others organizational. These include [49]:

a. The extent of infrastructure standardisation among the existing application silos of the current state architecture

b. The complexity and degree of customisation and integration of the current state architecture.

c. The willingness of lines-of-business to share infrastructure instead of "owning their own"

d. The extent to which the current state architecture must accommodate legacy systems

e. Past experience of the IT department in deploying technologies and concepts critical for clouds, such as standardisation, consolidation, virtualisation, clustering, and more

f. An effective governance structure is required to guide the cloud implementation to meet the business objectives of the organisation.

\section{CLOUD COMPUTING SERVICES}

Cloud architecture can be divided into the back end and front end. The front end is made visible to the user through connections to the Internet, allowing user interactions with the system [29]. The back end comprises the various cloud services models.

A. Infrastructure as a Service (IaaS): The IaaS layer is one of the key computing paradigm offered by the cloud service provider over the network. It offers various type of hardware resources in the form of service, for instance, Central Processing Unit (CPU), virtual machine (VM), memory, storage and network devices, etc [30]. The main advantage of the VM is to play the role of the server, so the VM has the same capability of the in-house server. This important layer facilitates instead of keeping the infrastructure, the users can be utilised by lease or rent according to their respective demand. The Virtualization is broadly used 
in the IaaS cloud concerning integrating/ decompose physical resources in an ad hoc basis to encounter growing or shrinking resource demand from the respective * cloud consumers $[2,31]$.

The main advantage for the users to decide CPU usage, size of memory, bandwidth, etc, instead of setting up an expensive server, data centers, etc. The users benefited by service provides relaxation by not worrying about infrastructure, also help by reducing high investment at the beginning of organization. In In the case of IaaS, the hardware part is fully controlled by the service provider, clients do not have any control over infrastructure but a user can manage and control the software and other applications accordingly. Top IaaS Cloud Computing Companies: Amazon (EC2), Rackspace, GoGrid, Microsoft, Terremark, Elastic Compute Cloud service and Google [32, 33].

\section{Examples of IaaS:}

a. Content Delivery Networks (CDNs): CDNs record user content and files to improve the system performance, for instance, speed and the cost associated with the delivery content for web-based systems. This is a useful platform for delivering large amounts of content closer to the end-user [41].

b. Backup and Recovery: This provides the ability for seamless backup and restoration of files [42].

c. Compute: This involves server requirements for maintaining cloud systems that can be configured and provisioned dynamically [44].

d. Storage: Highly scalable storage ability useful for recording activities of applications, file backups and recovery and storing files are also available [43].

B. Platform as a Service (PaaS): The PaaS layer in cloud computing provides a combination of both infrastructure and application by a cloud service provider (CSP). PaaS works with the combination of both, infrastructure and application by CSP, to facilitate the user to develop and deploy their respective applications [2, 34]. Which also provide all the services for developing, modifying, testing and running applications in the cloud environment, the platform helps to use $(\mathrm{C}, \mathrm{C}++$, .NET, etc) without investing in softwares.

PaaS facilitates to use the platform for multiple users to run their same application at a time. Additionally PaaS model allows resources to be easily increased with the demand of end-users to share the same cloud. It provides additional tools for development are database, web server, etc. Hence, the infrastructure of PaaS underlying operating system, storage and the network is managed by CSP. Besides, the users have control over their applications and respective data [35, 36]. PaaS facilitates the user to follow the complete software development life cycle, such as planning to deployment of the software.

Therefore, in contrast to SaaS, the solution of PaaS requires staff with IT capabilities to systematically manage their application development and deployment process accordingly. Migrating to PaaS platform, a client needs to investigate the provider's technical capabilities, like the ability to support multitenancy and scalability [37]. The client also requires software management issues like the types of the application lifecycle, applications management and the support of Application Programming Interfaces (API). Focusing on data and application management issues such as programming languages supported and availability of the log data. The other issue regarding the SLA that apply with PaaS solution. Top PaaS Cloud Computing Companies: Salesforce.com, Google, Citrix, Concur Technologies, Ariba, Unisys, LunaCloud, Microsoft Windows Azure, Apps Engine and Cisco [32, 33, 37].

\section{Examples of PaaS [44, 46]:}

a. Business Intelligence.

b. Database.

c. Development and Testing.

d. Integration.

e. Application Deployment.

C. Software as a Service (SaaS): In the SaaS layer, it provides a software delivery model, to run various software applications through the Internet without installing these in the client site [30]. This avoids installing the required software's by the end-user [36] and respectively saving the purchasing cost of this software. But end-users do not have any sort of control over cloud infrastructure, which is managed by the cloud service provider [38]. In SaaS different cloud consumers applications are organized in a single logical environment in the cloud to achieve the scale of economies and optimization in terms of speed, security, availability, disaster recovery and maintenance $[2,31$, 36].

The service provider entirely controls the infrastructure for instance servers, software's, etc and enable the enduser to use the applications and possibly application configuration settings. Furthermore, in SaaS, there is Divided Cloud and the mechanism of Convergence coherence, where every data item has either the "Read / Write Lock" [40]. Enterprises benefit by reducing operation costs by the adoption of SaaS service [3, 4] 
Furthermore, enterprises are also free from managing IT services and it helps them to focus on their core business activities [39]. Although CSP takes responsibility of maintaining, upgrading, backing up and security, the main concern for many enterprises to adopt SaaS still represents the security, data location, segregation, access and integrity. Some examples of SaaS include - Google Apps, Microsoft Office 365, GT Nexus, Marketo and Trade Card.

\section{Examples of SaaS [44, 46]:}

a. Email and Office Productivity: Email applications, word editors and processors, spreadsheets applications, presentations applications are typical examples in this category.

b. Billing: There are applications designed to monitor and manage customer billing. This is determined by users' system usage and subscriptions to products and services.

c. Customer Relationship Management (CRM): CRM is typical call-center applications.

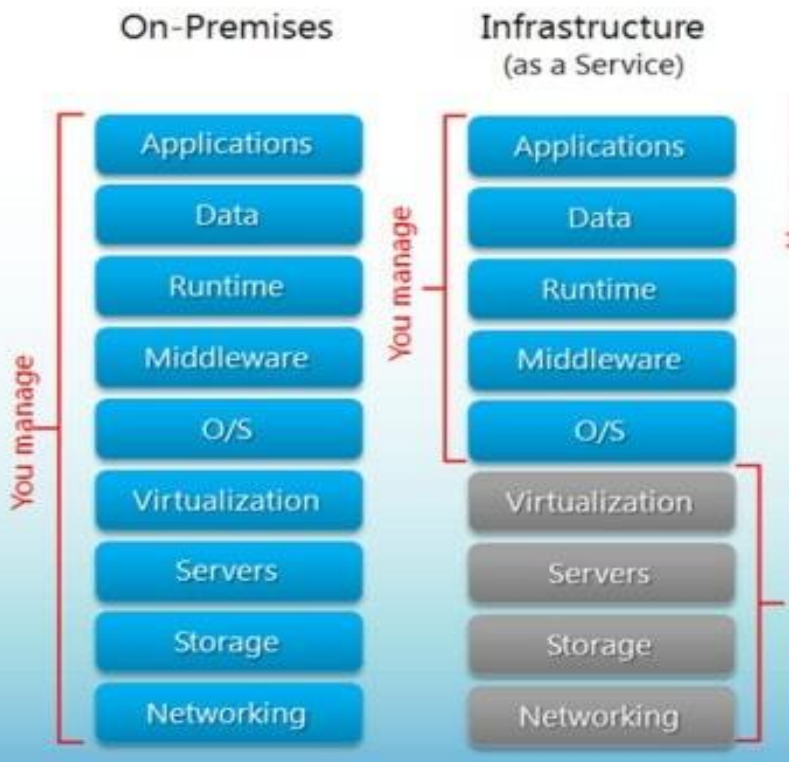

d. Financials: These are applications useful for tracking and reporting financial activities including the processing of expenditure, generating invoices, payroll, and managing taxes.

\section{THE KEY DIFFERENCES BETWEEN ON- PREMISE, SAAS, PAAS, IAAS.}

Now cloud platform is utilised for almost all your systems and processes. SaaS, PaaS, and IaaS are simply three ways to describe how you can use the cloud for your business and On-premise as your business [45].

- IaaS: cloud-based services, pay-as-you-go for services such as storage, networking, and virtualization.

- PaaS: hardware and software tools available over the internet.

- SaaS: software that's available via a third-party over the internet.

- On-premise: software that's installed in the same building as your business.

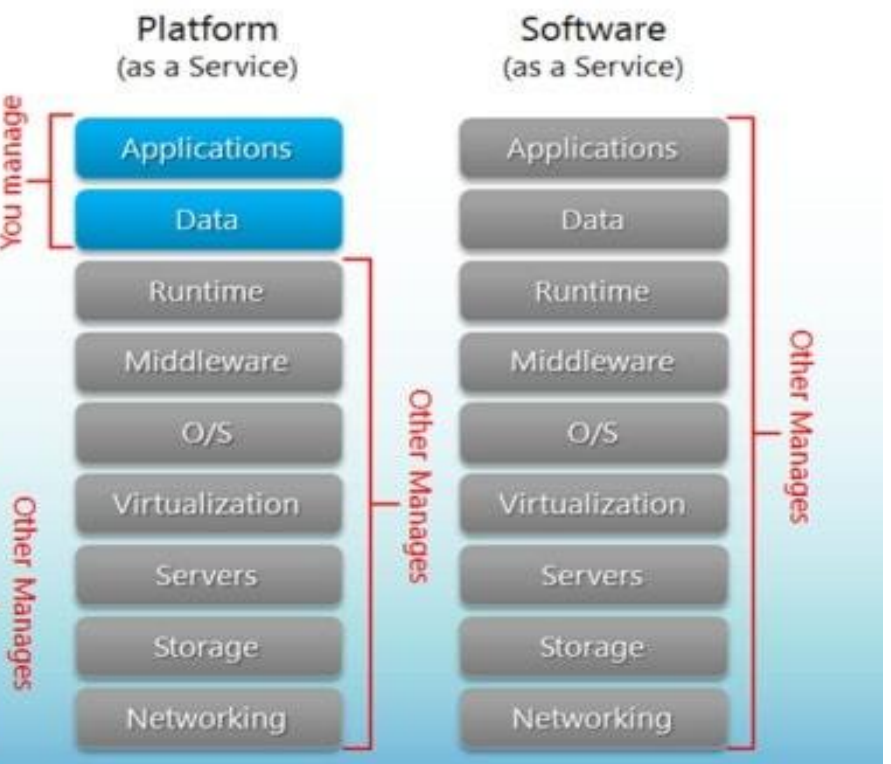

Source: Figure 1 [45]

Examples of SaaS, PaaS, and IaaS CC service models.

Most businesses use a combination of SaaS and IaaS CC service models, and some also engage developers to create applications using PaaS, too [45]. a. SaaS Examples: BigCommerce, Google Apps, Salesforce, Dropbox, MailChimp, ZenDesk, DocuSign, Slack, Hubspot.

b. PaaS Examples: AWS Elastic Beanstalk, Heroku, Windows Azure (mostly used as PaaS), Force.com, OpenShift, Apache Stratos, Magento Commerce Cloud.

c. IaaS Examples: AWS EC2, Rackspace, Google Compute Engine (GCE), Digital Ocean, Magento 1 
Enterprise Edition (can be either on prem or IaaS, but it is generally IaaS).

\section{DEPLOYMENT MODELS OF CLOUD COMPUTING BY NIST [27]:}

A. Public cloud. The cloud infrastructure is provisioned for open use by the general public. It may be owned, managed, and operated by a business, academic, or government organization, or some combination of them. It exists on the premises of the cloud provider [27]. A public cloud offer services at a low cost, with service on demand and high scalability [36].

B. Private cloud. The cloud infrastructure is provisioned for exclusive use by a single organization comprising multiple consumers (e.g., business units). It may be owned, managed, and operated by the organization, a third party, or some combination of them, and it may exist on or off premises [27, 35].

C. Hybrid cloud. The cloud infrastructure is a composition of two or more distinct cloud infrastructures (private, community, or public) that remain unique entities [27, 35]. But these are bound together by standardized or proprietary technology that enables data and application portability (e.g., cloud bursting for load-balancing between clouds).

D. Community cloud. The cloud infrastructure is provisioned for exclusive use by a specific community of consumers from organizations that have shared concerns (e.g., mission, security requirements, policy, and compliance considerations) [27, 35]. It may be owned, managed, and operated by one or more of the organizations in the community, a third party, or some combination of them and it may exist on or off premises.

\section{DIFFERENCE BETWEEN IAAS AND VIRTUAL DATA CENTER.}

The differences between an IaaS cloud environment and a virtual data center are as follows [47]:

a. Standardisation of environment that an enterprise can benefit from the cloud and lower cost.

b. The clouds are fully automated, hence all the standardised procedure will require the use of automated applications to enhance execution.

c. Clouds are self-service, hence access is provided to every cloud consumer to particular workflow, which particularly translates such approval into the permissions required by the user. Therefore, a provider must offer self-service.

d. There could be other cloud types apart from a private cloud in an enterprise. Whereas, multitenancy allows the private cloud to be properly isolated while permitting high utilisation of resources in a cost-effective manner.

e. The architecture of cloud can also be seen in terms of an IT portfolio concerning different deployment types and economics, degree of standardization and automation. Whereas, an enterprise should expect only $15 \%$ of its application to be relevant for the present cloud and plan a gradual increase in percentage as events unfold.

f. With regards to the private cloud, it is better to start on a small scale to allow for understanding. However, it typically takes time before an organisation can appreciate the particular benefits of the cloud. Therefore, it is also better to maximize utilisation rate before expanding.

g. Particularly cloud is a shared environment and it better for the customers to enquire for expansion to defend further investment in a cloud infrastructure.

\section{CONCLUSION}

The emerging and promising model of $\mathrm{CC}$ result of positive changes in today's business environment. By discovering the latest trends of IT services as computing utilities of the new generation of business delivery model and benefits of CC architect development attract many companies are trying to benefit from the CC service component. The increasing pressure of cost, high expectation from customer and global competition in the IT industries are some of the factors of new demand on cloud architect development process. Therefore a goodquality cloud architecture has become a very important part of the CC architect development process. There are many issues regarding the CC architect, for instance, architect of computer, fault tolerance capability, load balancing, very important storage and security. Also, there are many other challenging issues due to lack of proper guidelines in the adopting cloud architect model. Therefore, traditional and new companies must review the major key factors to exist in the present competitive environment and to improve cloud architect development process. The storage provides a facility to client put valuable data into the cloud and without worrying about how it is stored or backed up. But, the main concern regarding cloud storage is reliability and its security.

Therefore, for the successful development of goodquality cloud architect, cloud architect developers must review and investigate all related major factors as well as analyse and discuss them with all the stakeholders involved. In this paper, we have discussed some important key factors related to the $\mathrm{CC}$ for cloud architecture development process from literature and provided important guidelines which would be helpful for cloud architect developers. Concerning our future 
work emphasis on investigating these factors empirically and particularly proposed a maturity model for cloud architect development process.

\section{REFERENCES}

[1] Journal: Cooperation-Aware VANET Clouds: Providing Secure Cloud Services to Vehicular Ad Hoc Networks. Authors Rasheed Hussain and Heekuck Oh. Journal of Information Processing Systems 10(1):103-118. DOI: 10.3745/JIPS.2014.10.1.103. March 2014 https://www.researchgate.net/publication/273105166_Cooperatio n-

Aware_VANET_Clouds_Providing_Secure_Cloud_Services_to_ Vehicular_Ad_Hoc_Networks

[2] Journal: Cloud Computing Adoption in Enterprise: Challenges and Benefits, Authors Raja Muhammad Ubaid Ullah, Dr.Kevan A. Buckley,Dr. Mary Garvey and Dr. Jun Li. International Journal of Computer Trends and Technology (IJCTT),@ 2019 by IJCTT Journal, Volume-67 Issue-6, Year of Publication: June 2019. ISSN: 2231-2803 United Kingdom. https://www.ijcttjournal.org/2019/Volume-67\%20Issue-6/IJCTTV67I6P116.pdfPage 93-104.

[3] Journal: A Survey Based Investigation for Cloud Computing Adoption Internationally. Authors Raja Muhammad Ubaid Ullah, Dr.Kevan A. Buckley,Dr. Mary Garvey and Dr. Jun Li. International Journal of Computer Trends and Technology (IJCTT) - Volume 67 Issue 4 - April 2019. ISSN: 2231-2803 United Kingdom. https://www.ijcttjournal.org/2019/Volume67\%20Issue-4/IJCTT-V67I4P122.pdf Page 106

[4] Journal: A Systematic Literature Review of Factors Affecting Cloud Computing Adoption Internationally. Authors Raja M. Ubaid Ullah, Dr.Kevan A. Buckley,Dr. Mary Garvey and Dr. Jun Li. International Journal of Computer Trends and Technology (IJCTT) - Volume 67 Issue 3 - March 2019. ISSN: 2231-2803 United Kingdom. https://www.ijcttjournal.org/2019/Volume67\%20Issue-3/IJCTT-V67I3P110.pdf Page 41

[5] Journal: Factors Analysis of the Adoption of Cloud Computing Adoption In England. Authors Raja Muhammad Ubaid Ullah, Dr.Kevan A. Buckley,Dr. Mary Garvey and Dr. Jun Li. International Journal of Computer Trends and Technology (IJCTT) - Volume 67 Issue 6 - June 2019. ISSN: 2231-2803 United Kingdom. https://www.ijcttjournal.org/2019/Volume67\%20Issue-6/IJCTT-V67I6P103.pdf Page 18-30

[6] Journal: The Challenges of Cloud Computing Adoption InForensic Science. Authors Raja Muhammad Ubaid Ullah, Dr.Kevan A. Buckley,Dr. Mary Garvey and Dr. Jun Li. International Journal of Computer Trends and Technology (IJCTT) - Volume 67 Issue 6 - June 2019. ISSN: 2231-2803 United Kingdom. https://www.ijcttjournal.org/2019/Volume67\%20Issue-7/IJCTT-V67I7P106.pdfPage 40-48

[7] Conference: Adoption of Cloud Computing by SMEs in India: A study of the Institutional Factors. Completed Research Paper Author Jyoti M. Bhat (India). Proceedings of the Nineteenth Americas Conference on Information Systems, Chicago, Illinois, August 15-17, 2013.2 India. https://pdfs.semanticscholar.org/e35c/17887b3c2c79466725eb4a ad4abdf5e2c266.pdf

[8] Article: Cloud Computing and Computing Evolution. Authors Markus Böhm,Stefanie Leimeister,Christoph Riedl,Helmut Krcmar. January 2011. from IEEE Xplore. 978-0-7695-38402/09 \$26.00 @ 2009 IEEE. DOI 10.1109/CLOUD.2009.6. Germany.

https://www.researchgate.net/publication/268011245_Cloud_Co mputing_and_Computing_Evolution

[9] Conference: Adoption of Cloud Computing by SMEs in India: A study of the Institutional Factors. Completed Research Paper Author Jyoti M. Bhat (India). Proceedings of the Nineteenth
Americas Conference on Information Systems, Chicago, Illinois, August 15-17, 2013.2 India. https://pdfs.semanticscholar.org/e35c/17887b3c2c79466725eb4a ad4abdf5e2c266.pdf

[10] Conference: Design Comparison of Traditional Application and SaaS. Authors R. Vidhyalakshmi and Dr.Vikas Kumar. International Conference on Computing for Sustainable Global Development (INDIACom 2014), March 2014, India. https://www.researchgate.net/publication/263803712_Design_Co mparison_of_Traditional_Application_and_SaaS

[11] Conference: Architecture guidelines for SaaS development process. Authors SaiqaAleem, RabiaBatool, Faheem Ahmed, AsadKhatak and Raja Muhammad Ubaid Ullah. 2017 International Conference on Cloud and Big Data Computing, 2017 the 6th International Conference on Intelligent Information Processing. Venue: The University of Northumbria London Campus, Address: 110 Middlesex Street, London E1 7HT, UK, on September 17-19, 2017. DOI: 10.1145/3141128.3141136. https://www.researchgate.net/publication/322016191_Architectu re_guidelines_for_SaaS_development_process

[12] Study: A guide to cloud data. By Adrian Bridgwater (Specialist author on software engineering and application development). RACONTEUR. January 25, 2018. https://www.raconteur.net/technology/guide-cloud-data

[13] Report: Cloud Computing cloud look quite different in a few years. By John Buni. CLEANCLOUD, JUNE 2, 2019 7:19 PM. https://venturebeat.com/2019/06/02/cloud-computing-couldlook-quite-different-in-a-few-years/

[14] Report: Looking forward to the future of cloud computing. By Mark Samuels, December 11, 2018. RACONTEUR. https://www.raconteur.net/technology/future-cloud-computing

[15] Report: Cloud computing's next phase in business transformation. By Ben Rossi, January 25, 2018. https://www.raconteur.net/technology/cloud-computings-nextphase-business-transformation

[16] Report: It's Time to Think Beyond Cloud Computing. By Jeremy HSU. BACKCHANNEL, WIRED, 23-08-2017, 06:50 AM. https://www.wired.com/story/its-time-to-think-beyond-cloudcomputing/

[17] Report: The Most In-Demand Hard and Soft Skills of 2019. By Gregory Lewis, January 3, 2019. https://business.linkedin.com/talent-solutions/blog/trends-andresearch/2018/the-most-in-demand-hard-and-soft-skills-of-2018

[18] Report: Alibaba aims to make cloud computing its 'main business'. By Arjun Kharpal, CNBC Published Thu, Nov 82018 5:30 PM Est updated Tue, Dec 4 $201811: 51$ $\mathrm{PM}$ Est.https://www.cnbc.com/2018/11/09/alibaba-ceo-says-cloudcomputing-will-be-its-main-business-in-future.html

[19] Report: Customer Experience Is the Key Competitive Differentiator in the Digital Age. By Irving WladawskyBerger,Apr 20, 2018 1:52 pm ET. CIO JOURNAL. The Wall Street Journal. https://blogs.wsj.com/cio/2018/04/20/customerexperience-is-the-key-competitive-differentiator-in-the-digitalage/

[20] Press Release: Desktop as a Service Market $+49.38 \%$ CAGR with High Sales Volume Growth | Cisco Systems, Juniper Networks, Ibm, Published: Sept 1, 2018 6:01 a.m. ET. MarketWatch, https://www.marketwatch.com/press-release/desktop-as-aservice-market-4938-cagr-with-high-sales-volume-growth-ciscosystems-juniper-networks-ibm-2018-09-01

[21] Report: Multi-cloud strategy: 5 challenges you'll face. By Kevin Casey, May 29, 2018. The Enterprisers Project, A community of CIOs discussing the future of business and IT. https://enterprisersproject.com/article/2018/5/multi-cloudstrategy-5-challenges-you-11-face

[22] Report: What Google's burst of cloud announcements tells us about its overall strategy. By Jack Gold, April 27, 2019 8:45 
AM. https://venturebeat.com/2019/04/27/what-googles-burst-ofcloud-announcements-tells-us-about-its-overall-strategy/

[23] Report: Who are the leading providers of cloud services? By Helen Beckett, Technology / Cloud Business 2018. RCNT.EU/YZGXV, January 25, 2018. RACONTEUR. https://www.raconteur.net/technology/leading-providers-cloudservices

[24] Report: Which cloud solution should you choose? Public, private or hybrid?Technology / Cloud Business 2018. RCNT.EU/HSN72. RACONTEUR. http://res.cloudinary.com/yumyoshojin/image/upload/v1/pdf/clou d-for-business-2018.pdf

[25] Link: \#OPEN https://www.raconteur.net/tag/open-source

[26] Article: Architectural Principles for Cloud Software. Authors Claus Pahl, PooyanJamshidi and Olaf Zimmermann. ACM Transactions on Internet Technology 18(2), DOI: $10.1145 / 3104028$.

https://www.researchgate.net/publication/317348634_Architectu ral_Principles_for_Cloud_Software

[27] National Institute of Standards and Technology (NIST),NIST Cloud Computing Reference Architecture. Definition of Cloud Computing. Recommendations of the National Institute of Standards and Technology. Authors Fang Liu, Jin Tong, Jian Mao, Robert Bohn, John Messina, Lee Badger and Dawn Leaf, September

2011. https://nvlpubs.nist.gov/nistpubs/Legacy/SP/nistspecialpublicatio n500-292.pdf

[28] Cloud Computing Architecture.By Simplilearn. $5^{\text {th }}$ Jun, 2019. https://www.simplilearn.com/cloud-computing-architecturearticle

[29] Conference: International Conference Paper, Cloud computing security issues and challenges: A Survey. Authors Verma, A., \& Kaushal, S. (2011). A survey. Paper presented at the International Conference on Advances in Computing and Communications,

Kochi, India.https://www.researchgate.net/publication/220790184_Clou d_Computing_Security_Issues_and_Challenges_A_Survey

[30] Conference: Adoption of Cloud Computing by SMEs in India: A study of the Institutional Factors. Completed Research Paper Author Jyoti M. Bhat (India). Proceedings of the Nineteenth Americas Conference on Information Systems, Chicago, Illinois, August 15-17, 2013.2 https://pdfs.semanticscholar.org/e35c/17887b3c2c79466725eb4a ad4abdf5e2c266.pdf

[31] Journal: Cloud Computing - Research Issues, Challenges, Architecture, Platforms and Applications: A Survey. Authors Santosh Kumar and R. H. Goudar. International Journal of Future Computer and Communication, vol. 04, 2012. India. http://www.ijfcc.org/papers/95-F0048.pdf

[32] Conference: A comparative study of major service providers for cloud computing. Authors Noman Islam and Aqeel-ur-Rehman. September 2013. Karachi, Pakistan. https://www.researchgate.net/publication/258489864_A_Compar ative_Study_of_Major_Service_Providers_for_Cloud_Computin $\mathrm{g}$

[33] Book: What is Cloud Computing, Basic of Cloud Computing (PDF). Author Sourabh, February 11, 2014. http://sourcedigit.com/3623-cloud-computing-pdf-freedownload/

[34] Article: Cloud Computing and Computing Evolution. Authors Markus Böhm,Stefanie Leimeister,Christoph Riedl,Helmut Krcmar. January 2011. from IEEE Xplore. 978-0-7695-38402/09 \$26.00 @ 2009 IEEE. DOI 10.1109/CLOUD.2009.6. Germany.

https://www.researchgate.net/publication/268011245_Cloud_Co mputing_and_Computing_Evolution

[35] Journal: Public vs Private vs Hybrid vs Community - Cloud Computing: A Critical Review. Author Sumit Goyal. I.J.
Computer Network and Information Security, 2014, 3, 20-29 Published Online February 2014 in MECS (http://www.mecspress.org/) DOI: 10.5815/ijcnis.2014.03.03. India. http://www.mecs-press.org/ijcnis/ijcnis-v6-n3/IJCNIS-V6-N33.pdf

[36] Conference: Secure Cloud Computing Benefits, Risks and Controls. Authors Mariana Carroll, Alta van der Merwe and Paula Kotzé. September 2011. DOI: 10.1109/ISSA.2011.6027519 Source: IEEE Xplore Conference: Conference: Information Security South Africa (ISSA), 2011. South Africa. https://www.researchgate.net/publication/224259118_Secure_clo ud_computing_Benefits_risks_and_controls

[37] Book: Basic Cloud Computing Types. In: Cloud Computing Basics. Author Srinivasan, S. First online $15^{\text {th }}$ May 2014. SpringerBriefs in Electrical and Computer Engineering. [Online]. New York, NY: Springer New York, Pages. 17-41. http://link.springer.com/10.1007/978-1-4614-7699-3

[38] IEEE International Conference:Cloud Computing: Issues and Challenges. Authors Tharam Dillon, Chen Wu and Elizabeth Chang. (2010). In: 2010. 24th IEEE International Conference on Advanced Information Networking and Applications. [Online]. 2010, IEEE, pp. 27-33. Australia. http://ieeexplore.ieee.org/lpdocs/epic03/wrapper.htm?arnumber= 5474674

[39] Article: Adoption of Software as a Service (SaaS) Enterprise Resource Planning (ERP) Systems in Small and Medium Sized Enterprises (SMEs). Author Ravi Seethamraju. Information Systems Frontiers. 17 (3). p.pp. 475-492. Published $27^{\text {th }}$ May 2014.

Australia. http://www.academia.edu/18892212/Adoption_of_Software_as_ a_Service_SaaS_ERP_systems_in_SMEs

[40] Paper: Cloud Computing Building a Framework for Successful transition,

http://www.gtsi.com/cms/documents/WhitePapers/CloudComputing.pdf

[41] Content Delivery Networks (CDN) Versus Cloud Computing: What's the Difference and Do I Need Both? Author David Heidgerken, May 7, 2019. https://www.inap.com/blog/cdnversus-cloud-computing-whats-difference-do-i-need-both/

[42] Cloud disaster recovery (cloud DR). Author Margaret Rouse.https://searchdisasterrecovery.techtarget.com/definition/cl oud-disaster-recovery-cloud-DR

[43] Cloud storage.https://en.wikipedia.org/wiki/Cloud_storage

[44] Cloud Taxonomy, http://cloudtaxonomy.opencrowd.com

[45] Paper: IaaS vs PaaS vs SaaS Enter the Ecommerce Vernacular: What You Need to Know, Examples \& More. Author Tony Hou.https://www.bigcommerce.com/blog/saas-vs-paas-vsiaas/\#the-key-differences-between-on-premise-saas-paas-iaas

[46] What is SaaS, PaaS and IaaS? With examples. https://stackoverflow.com/questions/16820336/what-is-saaspaas-and-iaas-with-examples

[47] Private cloud: get it right and exploit its energy economics. Author C. W. Buyer, pp. 1-6, 2012. http://cdn.ttgtmedia.com/rms/computerweekly/CWE_BG_Mar\% 20Apr2012_privatecloud.pdf

[48] Cloud Computing Architecture.From Wikipedia. https://en.wikipedia.org/wiki/Cloud_computing_architecture

[49] An Oracle White Paper in Enterprise Architecture: "Architectural Strategies for Cloud Computing". August 2009. http://www.oracle.com/us/ciocentral/architecrl-strategies-for-cc396213.pdf 